\title{
Introducción general Desde la seguridad, la justicia $y$ los Derechos Humanos ${ }^{1}$
}

https://doi.org/10.21830/9789585287860.00

\author{
Jaime Cubides-Cárdenas ${ }^{2}$ \\ Escuela Militar de Cadetes "General José María Córdova” \\ Paola Alexandra Sierra-Zamora ${ }^{3}$ \\ Escuela Superior de Guerra "General Rafael Reyes Prieto"
}

El origen y desarrollo de un conflicto en determinada sociedad obedecen a múltiples causas. Dentro de las más comunes se encuentran las relaciones de poder,

1 Este capítulo presenta de forma conjunta los resultados de dos proyectos de investigación: "Perspectivas de seguridad y defensa en escenarios de paz y pos-acuerdo: el caso del Ejército Nacional de Colombia" del grupo de investigación de Ciencias Militares de la Escuela Militar de Cadetes "General José María Córdova", categorizado en B por Minciencias y con código de registro COL0082556. Y el proyecto de investigación "Las Fuerzas Militares de Colombia ante el macro delito en el diseño de políticas de seguridad y defensa nacional" del grupo de investigación Masa Crítica de la Escuela Superior de Guerra "General Rafael Reyes Prieto" categorizado en B por Minciencias y con código de registro COL0123247. Los puntos de vista y los resultados de este capítulo pertenecen a los autores y no reflejan necesariamente los de las instituciones participantes.

2 Abogado y especialista en Derecho Público de la Universidad Autónoma de Colombia. Especialista y magíster en Docencia e Investigación con énfasis en las Ciencias Jurídicas de la Universidad Sergio Arboleda, y magíster en Derecho de la misma casa de estudios. Investigador senior reconocido y categorizado por Minciencias. Docente investigador de la Facultad de Relaciones Internacionales de la Escuela Militar de Cadetes "General José María Córdova”, Bogotá, D. C., Colombia. ORCID: https://orcid.org/0000-0002-6542-6892. Contacto: jaime. cubides@esmic.edu.co

3 Abogada de la Universidad Católica de Colombia. Magíster en Derechos Humanos, Democracia y Justicia Internacional por la Universitat de València, Espańa. Doctorado (en curso) del Programa de Derechos Humanos, Democracia y Justicia Internacional por la Universitat de València, España. Investigador junior reconocido y categorizado por Minciencias. Docente investigadora de la Escuela Superior de Guerra «General Rafael Reyes Prieto", Bogotá, D. C., Colombia. orcid: https://orcid.org/0000-0002-3146-7418. Contacto: paola.sierra@ esdegue.edu.co 
las disputas económicas, las de carácter ideológico y territorial. En ocasiones, estas se resuelven en periodos cortos. No obstante, en otras el conflicto se torna prolongado y violento, como ocurrió en la Gran Guerra y la posterior Segunda Guerra Mundial, en diversas guerras de alcance regional o incluso en los conflictos internos y en las dictaduras nacionales. Este último escenario se ha presentado en los casos de Colombia, Chile y Argentina, en América Latina, o Burundi y la República Democrática del Congo, en África (Moreno \& Sierra, 2018).

En varias situaciones, el conflicto se ha agudizado hasta el punto de presentar graves violaciones de los Derechos Humanos, y ha ocasionado una evidente fractura en los planos social, cultural, económico, psicológico, etc. Pero también, luego de fases de extrema violencia, emana casi por sí sola la paz y el cese de las hostilidades. En ese lapso o "posfase", los actores del conflicto someten sus diferencias a una negociación política (proceso que ha tenido lugar en Colombia en años recientes), mediante la cual se hacen concesiones recíprocas para dar por terminada la confrontación. En otras palabras, se lleva a cabo un proceso que se denomina justicia transicional $(\mathrm{JT})^{4}$.

La finalización de tales conflictos a través de la justicia transicional es el mecanismo que posibilita iniciar un proceso de reparación a las víctimas por causa de las masivas violaciones de los Derechos Humanos (Cubides-Cárdenas \& Sierra-Zamora, 2018). Dicho mecanismo tuvo sus orígenes en los Tribunales de Núremberg, creados para sancionar crímenes de guerra y de lesa humanidad cometidos durante la Segunda Guerra Mundial, momento a partir del cual se hizo evidente la tensión entre el anhelo de justicia y la consolidación de la paz. Una serie de hechos que han demostrado que no basta la reparación integral de las víctimas si los victimarios persisten en no reconocer la violación masiva de los Derechos Humanos (Cubides-Cárdenas \& Sierra-Zamora, 2018).

En el diseño de esta nueva justicia transicional no solo han participado los actores del conflicto nacional interno, representados por parte del Estado mediante sus órganos legislativo y judicial, sino también su órgano administrativo. Aunque mucho se ha dicho acerca de la importancia de emplear respuestas coordinadas de carácter civil y militar para alcanzar esa alineación estratégica en la implementación de los acuerdos de paz, pocos estudios han abordado este tema y, por lo tanto, no se cuenta con mucha información pese a su importancia para desarrollar los puntos pactados en el acuerdo de paz en el conflicto colombiano.

4 Para profundizar sobre esta noción, véase Cubides-Cárdenas, Suárez y Sierra (2018). 
Esta situación genera varias incertidumbres sobre la protección de los Derechos Humanos en escenarios de "posacuerdo". Al respecto, se debe tener en cuenta lo que ocurre actualmente en territorios de índole rural en Colombia (Lugo, 2015, pp. 13-18). En particular, los programas de reparación de víctimas y la implementación de la justicia transicional (Cubides-Cárdenas, Sierra-Zamora \& Mejía, 2018; Orjuela \& Lozano, 2012, p. 260).

Tal como ha sido destacado por varios investigadores (Arango, 2012; Castillejo-Cuéllar, 2014; Gómez \& Rodríguez, 2016; Jaramillo, 2012; Peralta, 2011; Salamanca, 2015; Sarmiento, 2016; Villa \& Insuasty, 2015), en lo que concierne a la protección de los Derechos Humanos en escenarios de posconflicto, es necesario considerar las experiencias de otras regiones, Estados, tribunales ad hoc y comisiones de verdad (Millán, 2015).

Esto es necesario porque existen antecedentes que aportan valiosas lecciones para que Colombia enfrente los retos que espera superar (Harvey, 2013), como reconstruir la sociedad después del extenso conflicto armado y reparar a las víctimas garantizando la no repetición (Valdivieso, 2012, pp. 637-626). En última instancia, esto debe ser resultado de la justicia restaurativa (Torres \& Alonso, 2015). Hoy por hoy, Colombia atrae hacia sí todas las miradas en el mundo por ser el "gobierno proyectante" para consolidar una paz verdadera y duradera, encaminada a la resolución final del conflicto (Gamboa \& Herrera, 2012, p. 250; Patińo \& Ruiz, 2015, p. 218). Así lo reitera la Corte Constitucional en su jurisprudencia:

Los derechos de las víctimas del conflicto armado colombiano son fundamentales y tienen protección constitucional. Es por ello que el Estado tiene como deber garantizar su protección y ejercicio, estableciendo medidas que les permitan a los afectados conocer la verdad de lo ocurrido, acceder de manera efectiva a la administración de justicia, ser reparados de manera integral y garantizar que los hechos victimizantes no se vuelvan a repetir. (Sentencia T-083, 2017)

De esta forma, la nueva justicia transicional en escenarios de "posacuerdo" en Colombia tiene la meta de salvaguardar a todas las víctimas del conflicto, de manera muy especial en el aspecto de su planeamiento y ejecución. Ello exige elaborar un censo de las víctimas que deben ser escuchadas y formar parte en el proceso, así como crear comisiones donde se revele la verdad de lo ocurrido y se establezca la no repetición de nuevos hechos de violencia. Por esto mismo, el gobierno nacional ha implementado un enfoque diferencial de corte generacional en la creación de mecanismos orientados a la reparación integral de las víctimas del conflicto armado, todos ellos en el marco de la justicia transicional (Rodríguez, Chacón \& CubidesCárdenas, 2017, p. 44). En palabras de la Corte Constitucional: 
La justicia transicional implica la articulación de un conjunto de medidas judiciales, o extrajudiciales, y puede abarcar el enjuiciamiento de personas, el resarcimiento de antecedentes, la remoción del cargo o combinaciones de todas las anteriores, tal como lo ha reconocido el Consejo de Seguridad. (Sentencia C-649, 2015)

Y todo esto para lograr entender y articular, de la mejor manera posible, la trayectoria jurisprudencial y el pacto que se hizo tras la firma del acuerdo de paz, junto con la alineación estratégica para que los mecanismos que han sido integrados en la justicia transicional conlleven, en buena medida, los requerimientos "multiactivos” que emanan de su implementación (Cubides-Cárdenas et al., 2018, p. 19).

La exposición anterior permite entender la estructura y el desarrollo de los contenidos de este libro. El texto está dividido en cinco capítulos, en los cuales los autores demuestran la importancia de analizar los contextos de la seguridad y defensa nacionales, así como la construcción social que se lleva a cabo con la implementación del acuerdo de paz entre el Estado colombiano y las FARC. Es en este escenario donde el gobierno de Colombia debe luchar incansablemente por su constante implementación y articulación.

En el primer capítulo se expone una aproximación alrededor de lo que, en el contexto mencionado, se consideraría como el fenómeno amenazante por excelencia para la seguridad y la defensa de los países, a saber, las relaciones internacionales en un sistema-mundo globalizado y sus repetidas crisis. Tal situación permea y repercute en el análisis de amenazas tradicionales y redefine el nuevo papel de las amenazas que enfrenta hoy el Estado y los entes globales. Los autores abordan esta temática desde la sociología, la ciencia política y el derecho.

El eje central del capítulo son los ataques sobre la actividad internacional. Desde esta perspectiva, los autores analizan los ciberataques atribuidos al crimen transnacional organizado y examinan las organizaciones antisistémicas violentas, es decir, todo lo que cubre este marco que ha sido denominado sharp power. Se puede afirmar que el ingrediente más valioso del capítulo es que explica el modus operandi de estas organizaciones y de qué manera la seguridad y la defensa se deben articular en cumplimiento de los intereses del Estado.

En el segundo capítulo los autores buscan establecer los parámetros que emplea la jurisprudencia de la Corte Interamericana de Derechos Humanos (Corte IDH) para tratar los procesos de la denominada justicia transicional, mecanismo empleado en Colombia para definir el desarrollo de los procesos y el tipo de juzgamiento por parte de la Jurisdicción Especial para la Paz. Al mismo tiempo, proponen determinar este tipo de aplicación, pues esta intervención judicial implica la no vulneración de estándares nacionales e internacionales. Es importante destacar cómo la 
aplicación de estas medidas supone también un desarrollo exhaustivo y concreto del Control de Convencionalidad (CCV), que, por supuesto, permitiría armonizar la aplicación de este tipo de medidas entre la Corte Interamericana de Derechos Humanos y el ordenamiento jurídico nacional. De este modo, la verificación de los principios de legalidad y legitimidad que avocan estas medidas internas ha de involucrar la configuración de nuevos roles en el pensamiento jurídico constitucional5.

En el capítulo tercero los autores desarrollan la figura de la justicia transicional, específicamente las comisiones de la verdad y los procesos judiciales similares que han ocurrido en otras partes del hemisferio. En este escenario, los operadores jurídicos desempeñan un nuevo papel en la aplicación de la justicia transicional en el marco del acuerdo de paz y la protección de los Derechos Humanos. De ahí que sea vital encontrar un eje que permita comparar el proceso colombiano con el de otros países, ya que esas experiencias le sirven a Colombia para implementar el acuerdo de paz y lograr la articulación estratégica que se ha mencionado a lo largo de esta presentación.

El cuarto capítulo aborda los múltiples aspectos del conflicto en tres ejes principales. Primero, caracteriza la manera como se ha entendido el conflicto armado en Colombia. Segundo, identifica cómo los gobiernos colombianos han interpretado el conflicto armado y, tercero, establece unas conclusiones desde la perspectiva actual del conflicto armado.

Finalmente, el capítulo quinto tiene una trascendencia muy significativa e importante para esta obra, pues describe y analiza los hechos que contribuyen a explicar e interrelacionar las dinámicas regionales de los diferentes actores presentes en Bojayá, Chocó. De esta forma, se pretende que la búsqueda por el reconocimiento y el desarrollo de los hechos de victimización de Bojayá, desde la interpretación que ofrecen la construcción de memoria y la reivindicación de las manifestaciones de la sociedad civil, sean parte integral de los nuevos papeles que asume la justicia transicional en nuestros días.

En consecuencia, se deja claro que, desde el estudio que se presenta, la dinámica local, nacional y regional involucra, en todas sus formas, diversas relaciones que se tejen y reconstruyen con actores que viven el día a día de la violencia. Con esto se puede sintetizar que el conflicto armado en Colombia (sobre todo el que se vive en Bojayá) ha alcanzado un margen de consolidación en los procesos organizativos para el tipo de comunidades que abogan por este territorio. Y, por supuesto, no menos importante, que los procesos de memoria fortalecen, con todas sus posibilidades, el tejido social, fundamento para construir una nueva sociedad colombiana.

5 Para profundizar en el tema, véase Sierra-Zamora, Cubides-Cárdenas y Carrasco (2016). 
Así, y confiando en que las discusiones presentadas en esta obra aportarán a los retos enmarcados en el acuerdo de paz y en el papel del hemisferio en cuanto a seguridad y defensa, deseamos una excelente lectura.

Bogotá, junio de 2020

\section{Conflicto de intereses}

Los autores declaran que no existe ningún potencial conflicto de interés relacionado con este capítulo.

\section{Financiación}

Los autores no declaran fuente de financiamiento para la realización de este capítulo.

\section{Referencias}

Arango, Ó. F. A. (2012). Geografias de la memoria: posiciones de las víctimas en Colombia en el periodo de justicia transicional (2005-2010). Bogotá, D. C.: Pontificia Universidad Javeriana. Recuperado de https://repository.javeriana.edu.co/bitstream/handle/10554/42499/9789587167986vp.pdf?sequence $=1$ \&isAllowed $=y$

Castillejo-Cuéllar, A. (2014). La localización del dańo: etnografía, espacio y confesión en el escenario transicional colombiano. Horizontes Antropológicos, 20(42), 213-236.

Cubides-Cárdenas, J., \& Sierra-Zamora, P. A. (2018). Reparación integral de las víctimas en la justicia transicional: historia, debate y actualidad dentro del Acuerdo de Paz firmado por el gobierno de Colombia y las FARC-EP. En Derecho procesal constitucional. Codificación procesal constitucional (pp. 31-64). Bogotá, D. C.

Cubides-Cárdenas, J., Sierra-Zamora, P. A., \& Mejía, J. (2018). Reflexiones en torno a la justicia transicional en Colombia: Fuerzas Armadas, víctimas y posacuerdo. Utopia y Praxis Latinoamericana, 23, 11-24.

Cubides-Cárdenas, J., Suárez, S., \& Sierra-Zamora, P. (2018). El Derecho Internacional Humanitario y la Corte Interamericana de Derechos Humanos en la protección de los derechos de verdad y justicia a las víctimas del conflicto armado interno colombiano. En J. Cubides-Cárdenas \& A. Fajardo (Coords.), Cuestiones dialécticas en torno a los Derechos Humanos y la paz (pp. 164-186). Brasil: Instituto Memoria Editora \& Projetos Culturais.

Gamboa Tapias, C. d., \& Herrera Romero, W. (2012). Representar el sufrimiento de las víctimas en conflictos violentos: alcances, obstáculos y perspectivas. Revista Estudios Socio-Jurídicos, 14(1), $215-254$. 
Gómez, J. D. V., \& Rodríguez, A. I. (2016). Significados en torno a la indemnización y la restitución en víctimas del conflicto armado en el municipio de San Carlos. El Ágora USB, 16(1), 165-191.

Harvey, E. (2013). Corte Constitucional y conflicto armado. Control de políticas sociales en el marco del conflicto en Colombia. Revista de la Facultad de Derecho y Ciencias Politicas, 42(117), 425-453. https://revistas.upb.edu.co/index.php/derecho/article/view/1642

Jaramillo, P. (2012). Deuda, desesperación y reparaciones inconclusas en La Guajira, Colombia. Antipoda. Revista de Antropología y Arqueología, 14, 41-65.

Lugo, J. P. V. (2015). Memorias emergentes: las consecuencias inesperadas de la Ley de Justicia y Paz en Colombia (2005-2011). Revista Estudios Socio-Jurídicos, 17(2), 13-44.

Millán Hernández, J. A. (2015). Comisiones de la verdad y posibles aprendizajes para el caso colombiano. Papel Político, 20(2), 425-459.

Moreno, D., \& Sierra, P. A. (2018). El derecho efectivo al retorno de las victimas por abandono o despojo forzado de tierras: análisis de casos emblemáticos de Bolivar, Valle del Cauca, Antioquia y Cesar 2012-2017 (Tesis de pregrado). Universidad Militar Nueva Granada, Bogotá, D. C., Colombia.

Orjuela Ruiz, A., \& Lozano Acosta, C. (2012). La indeterminación del campo de la justicia transicional en Colombia. Revista Estudios Socio-Jurídicos, 14(1), 255-281.

Patińo Mariaca, D. M., \& Ruiz Gutiérrez, A. M. (2015). La justicia restaurativa: un modelo comunitarista de resolución de conflictos. Revista de la Facultad de Derecho y Ciencias Políticas, 45(122), 213-255.

Peralta González, L. C. (2011). Finding truth in Colombia: epistemological tensions? Revista Opinión Jurídica, 10(20), 147-158.

República de Colombia. (2015). Sentencia T-649. Corte Constitucional. Recuperado de https://www. corteconstitucional.gov.co/relatoria/2015/t-649-15.htm

República de Colombia. (2017). Sentencia T-083. Corte Constitucional, magistrado ponente Alejandro Linares Cantillo. Recuperado de https://www.corteconstitucional.gov.co/relatoria/2017/T-083-17.htm

Rodríguez Bejarano, C., Chacón Triana, N., \& Cubides-Cárdenas, J. (2017). Reclutamiento ilícito de niños y niñas en Colombia: marcos de protección en el Derecho Internacional de los Derechos Humanos. En J. Cubides-Cárdenas (Ed.), Desafíos contemporáneos de la protección de los Derechos Humanos en el Sistema Interamericano (pp. 31-55). Bogotá, D. C.: Universidad Católica de Colombia.

Salamanca, C. A. (2015). Bahía Portete, la masacre y el ritual. Violencia masiva, mediaciones y prácticas transversales de memoria en La Guajira. Antipoda. Revista de Antropología y Arqueología, 21, 121-143.

Sarmiento, J. P. E. (2016). Justicia transicional sin transición: el caso de la masacre de Nueva Venecia. Co-Herencia, 13(24), 181.

Sierra-Zamora, P. A., Cubides-Cárdenas, J., \& Carrasco, H. (2016). El Control de Convencionalidad: Aspectos generales en el sistema interamericano de derechos humanos y en el derecho colombiano. En J. Cubides-Cárdenas (Ed.), El control de convencionalidad (CCV): Fundamentación e implementación desde el Sistema Interamericano de Derechos Humanos (pp. 51-88). Bogotá, D. C.: Universidad Católica de Colombia. Recuperado de https://repository.ucatolica.edu.co/ bitstream/10983/14400/4/control-de-convencionalidad.pdf 
Torres, T., \& Alonso, J. (2015). Violencia política y guerra sucia en Colombia. Memoria de una víctima del conflicto colombiano a propósito de las negociaciones de La Habana. Memoria y Sociedad, 19(38), 9.

Valdivieso Collazos, A. M. (2012). La justicia transicional en Colombia. Los estándares internacionales de Derechos Humanos y Derecho Internacional Humanitario en la política de Santos. Papel Politico, 17(2), 621-653.

Villa Gómez, J. D., \& Insuasty Rodríguez, A. (2015). Significados en torno a la reparación, la ayuda humanitaria, la indemnización y la restitución en víctimas del conflicto armado en el municipio de San Carlos. El Ágora USB, 15(2), 419-445. 